\title{
A Case Study on Student-Run Official WeChat Account in Chinese Colleges and Universities
}

\author{
Ruilan Cao \\ School of Foreign Languages \\ Anhui University of Technology \\ Ma'anshan, P. R. China
}

\author{
Xinrui Yan* \\ College of Communication \\ Boston University \\ Boston, United States \\ *Corresponding Author
}

\begin{abstract}
Emerging media, as a new and highly operational vehicle of information dissemination, has sprouted around the world in recent years, greatly undermining the power of traditional media. WeChat, as an emerging social platform, dominates Chinese new media market. In Chinese colleges and universities, WeChat is a highly popular social app. Many college students do their own media via Official WeChat Account (subscription). Despite of the new forms that have brought numerous benefits, challenges such as attracting fans, content quality and creativity still exist given the limitations of We Media or "self media" and the immaturity of student-run media. To overcome these challenges, strategies should be adopted to deal with each challenge, which will be the major discussion of the essay.
\end{abstract}

Keywords-New new media; Official WeChat Account; college students; challenges; strategies

\section{NEW NEW MEDIA AND WECHAT}

The term "new new media" is generally called "new media" by the masses or "emerging media" which differs from traditional media such as newspaper or television, but Paul Levinson's classification of media in different stages fully depicts the features of media evolution, and this essay will adopt his way of naming the kind of media that gives access for everyone to disseminate ideas around the world. According to Paul Levinson, the difference between new media and new new media lies in the interactive function of the later [1]. Amazon and Baidu are clearly new media, but a netizen cannot really be a part of the process and make interactions while Facebook and WeChat are imbued with new social functions and each person can be an information disseminator and content creator.

Nevertheless, WeChat, a magnificent combination of Facebook, YouTube and other powerful social platforms facilitates people's lives to a great extent and at the same time, caters to people's social thirst and desire for publishing for themselves. According to 2016 Statistics about WeChat Users, the number of daily users is up to 570 million, about $80 \%$ of which subscribed Official WeChat Account and $21.9 \%$ of them subscribed we media account which is run by individual mostly. In 2017, the Report of WeChat Accounts and Ecology Research announces that the number of active account reaches 889 million while that of QQ is only 868million. Besides, student account took up $19.70 \%$ of all users in 2016 . This essay

Supported by National Social Science Foundation of China (Project No. 15BYY024), by Excellent University Youth Talents Supporting Program of Anhui Province, China (Anhui Education Personnel [2014] Reference No. 181), by Teaching Team Project of AHUT focuses on challenges raised by managing Official WeChat Account in universities and probes into solutions and methods for improving the content quality as well as creativity.

\section{CHALLENGES}

When it comes to managing an Official WeChat Account, myriad problems crop up. Here we will mainly deal with the challenges and strategies of attracting fans as well as those of crafting quality content and further improvements. The first one is universal for all account administrators, but especially tough for college students, and the later has more to do with college students' inexperience and lack of professional knowledge.

\section{A. Attracting Fans}

One of the most crucial goals for most account administrators is to attract as many fans as possible given that the number of fans is a great indicator of how influential an account is, and for some, it also means more profit by posting articles for some advertisements on condition that the number of reads and followers are usually above 5000. Generally, student-run Official WeChat Account does not include writing profit-oriented articles. Their focus is mainly about school activities, language learning or sharing their own travel and other experience in their lives. Thus, the content is not about profitability with large fan base such as lifestyle or travel or fashion influencers given the limited life experience of most students.

There are many cases concerning this issue, so Anhui University of Technology is cited as an example. Most of the subscriptions are concerned with school activities for different programs, and they have their own official accounts which are mainly for publicity or informing the audiences. However, in view of the interactivity of electronic text [2], WeChat administrators can immediately get feedback and interact with fans and followers. Subscribers can easily participate in activities online. For example, the voting activity is one of the most common one on campus whether it is for competition or statistical analysis. Therefore, it is entirely possible to attract more fans and increase reads by taking advantage of the interactive nature of WeChat account. But usually the number of subscribers and reads is in positive correlation with the size of a department and is obviously reflected in the WCI (WeChat 
Communication Index) collection. Here is one from Official Wechat Account of AHUT's Youth League Committee last

year [3] (2016):

TABLE I. The WCI INDEX ON THE 12Th WeEK OF ANHUI UNIVERSITY OF TeChNOLOGY IN 2016 (TRANSLATED)

\begin{tabular}{|c|c|c|c|c|c|c|c|c|}
\hline \multicolumn{9}{|c|}{ The WCI Index on the 12th Week of AHUT } \\
\hline School & Reads & Average Reads & Maximum Reads & Likes & Average Iikes & Maximum Likes & Like Rates & WCI \\
\hline Manangement Science and Engineering & 1072 & 209 & 301 & 1298 & 162.25 & 193 & 0.78 & 511.056 \\
\hline Academy of Art and Design & 2389 & 140.53 & 491 & 748 & 44 & 331 & 0.313 & 501.532 \\
\hline Electrical and Information Engineering & 1233 & 102.75 & 232 & 382 & 31.83 & 80 & 0.31 & 416.94 \\
\hline Material Science and Engineering & 753 & 94.125 & 241 & 244 & 30.5 & 152 & 0.324 & 373.28 \\
\hline Mathematics and Physics & 568 & 71 & 119 & 321 & 40.125 & 67 & 0.565 & 355.63 \\
\hline Business & 485 & 121.5 & 237 & 120 & 51 & 30 & 0.247 & 340.93 \\
\hline School of Public Management and Law & 572 & 114.4 & 199 & 141 & 28.2 & 47 & 0.247 & 340.93 \\
\hline Graduate School & 1987 & 110.39 & 333 & 29 & 1.61 & 5 & 0.0115 & 336.124 \\
\hline Civil Engineering and Architecture & 653 & 130.6 & 153 & 94 & 18.8 & 20 & 0.144 & 330.8 \\
\hline Chemistry and Chemical Engineering & 568 & 81.14 & 120 & 98 & 14 & 20 & 0.173 & 311.21 \\
\hline Computer Science and Technology & 438 & 87.6 & 153 & 80 & 16 & 26 & 0.183 & 298.852 \\
\hline Mechanical Engineering & 487 & 48.7 & 119 & 48 & 4.8 & 9 & 0.099 & 266.315 \\
\hline Environmental Engineering & 171 & 171 & 171 & 16 & 16 & 16 & 0.094 & 265.169 \\
\hline Foreign Langauges & 271 & 67.75 & 148 & 22 & 5.5 & 16 & 0.081 & 233.83 \\
\hline Metallurgical Engineering & 231 & 25.67 & 68 & 30 & 3.33 & 6 & 0.129 & 206.447 \\
\hline
\end{tabular}

It can be concluded that the target subscribers were either interested in the content or members of the department whose benefits were inextricably connected with the content. Thus, in running or managing official WeChat accounts, it is always vital to figure out what interest the subscribers and think from their perspectives so as to attract more fans.

\section{B. Crafting Quality Content}

Another significant aspect of student-run Official WeChat Account is the quality of the content. The purpose of developing new media is not merely about attracting more fans. What's more vital is to realize the betterment of the whole media atmosphere, among which good content quality should never to be too emphasized. However, good quality content does not only mean an article has to be didactic, but that a good content could be soothing, inspiring, positive, provocative, informative, etc.

Compared with some news media companies' official account, the content of student-run WeChat account is certainly less formal, prone to personal experiences and the use of internet buzzwords. This is not to say, being formal and flawless is the final pursuit since other entertainment-oriented media moguls also tend to use informal words to get closer to their audience. Quality content is more of the ideas spread to the public, and here it means the positive ones which encompass practical knowledge, tips, rule of thumb, informative subject sources, witty banter or humorous videos. However, the problem is that there are still many WeChat accounts run by students sharing negative ideas.

In spite of the ideas of the content, errors in spelling, grammar are also key problems. Most student-run official WeChat accounts belong to individual type that is only supervised by very few people. So there are not enough members doing the proofreading, which will lead to some mistakes in content. Some of them are apparent mistakes which slipped away from the eyes of the administrator, which may have negative influence on its popularity and some fans will not follow it with trust disintegrated. Some are not obvious, but they will presumably misguide the readers.

\section{STRATEGIES}

To overcome the two major challenges, different strategies should be adopted to effectively address the problems. The following has involved ways increasing or populating access or links to audience in terms of attracting fans and ways increasing the preciseness in terms of the betterment of content quality. Also, this part covers other aspects for further improvement such as creativity and "Pain Point".

\section{A. Attracting Fans}

In aims of attracting more fans, access to content is of great significance, so increasing ways to disseminate content is key for overcoming such challenges. This is usually very hard for college students as mentioned above. The following are some strategies for the challenge.

It should be noted that any strategy that attempts to attract more fans are based on preexisting fans who will serve as perfect access to more potential subscribers [4]. Through observing and drawing conclusions, this is usually achieved via three ways: (1) Sharing links on Moments (a function of WeChat to post pictures and share ideas, emotions, etc.) or QQ zone (a social platform to pictures and share ideas, emotions, etc.) or other platforms. (2) Introducing orally to friends and others. (3) Scanning QR code. Therefore, asking fans to share links for obtaining gifts, precious academic resources and the like is also a common strategy. As for scanning QR code, the code is mostly placed somewhere obvious, in both reality and cyberspace. For instance, the notoriously famous OFO and Mobike's (shared bikes) code is attached on the bike itself while for some discount on online course, you can always find it on the internet. So as regards to student-run subscriptions, student activities are of overriding importance to attract fans and the three approaches can be adopted simultaneously.

Additionally, another effective way is to interact with fans in a materialistic approach, for instance, asking them to participate in some contests held by this official account and send attractive gifts to readers. But the limitation is that the 
financial source is so limited for students, so this is naturally the last resort for merely gaining fans.

\section{B. Crafting Quality Content}

In order to improve the situation, there are two methods. One is that the administrator himself should be educated not to share very negative content. Another is that for the betterment of media environment, administrators need to make improvement through practice, this applies to those who do are uncertain about what would be the positive and desired content for readers. American positivist philosopher John Dewey once proposed that the best way to study is through practice: work in our hands [5]. This can apply to the creation of content and through numerous practice and research, one gets to know what the desired and positive content is and what will bring about positive effects instead of being blinded by his own spiritual pursuit.

When it comes to problems like grammar mistakes and the like, administrators ought to draw lessons from them and ensure that similar mistakes will not happen again. Additionally, it is also advisable, if allowed, to apologize publicly for the negligence. Finally, it is always a great policy to double or triple check them or ask for teachers or professionals to assist.

\section{Further Improvements}

After addressing those problems, there are other respects to be highlighted to make further improvements. The two most salient and pivotal ones are creativity and "pain points". Creativity either in content or in form is always an effective way to draw attentions, and pricking the "pain points" always bring about more resonance from the readers.

First, improvements in creativity. Creativity in content is a crucial point in the overall betterment for student-run official WeChat account. In running and managing "Huiling Translation Circle", we found that there are more active fans when there are more interesting columns apart from translation. Given that English translation skill is closely linked with crosscultural capacity, the platform also shares slang usage, interview with foreign friends about cultural differences as well as the currently hot "reader" column which is adopted in many subscriptions. "Reader" provides great access for everyone on campus to share their voices and perfect their pronunciation and most importantly, cultivate their interest in English speaking and reading. Therefore, in about one month, the subscribers reached nearly 300 given there were less than 300 students in the English department. "All things are difficult before they are easy," and as for this official WeChat account, we can see its bright future given the base of fans, provided that it keeps being innovative and rigorous in every step.

Second, attaching more importance to pain point in soft text. To make further improvements in WeChat running, utilizing the Pain Point in soft text is also pivotal. Pain Point is the readers' knot or the desire to be satisfied and the term is borrowed from a marketing term meaning the customers' issues or complex that they themselves are eager to get rid of. In China, WeChat and Sina Weibo are two dominating social software and many soft texts are gaining huge popularity.
These new new media platforms are so influential that may affect implementation of new policies. But it can be seen that most super popular bloggers are quite good at writing soft texts which is informal and usually characterized with self-mockery or self-trumpet blowing. For instance, the case study of Mimeng's strategy has shown some critical features of super popular official account run by individual. (Mimeng drew over 400 thousand fans in 2 months) It has salient traits of selfmockery and goes straight to the pain points of the large target readers who are mostly young women [6]. This rule also applies to student-run subscriptions. Most college students take tremendous interest in reading jokes or memes on the internet, some of which are pretty niche, and some adopt tons of internet buzzwords, so it is essential to cater to the readers and pricks their pain points so that a good resonance can be created, but all of the above mentioned should be based on the prior determining of the right target audience.

Official WeChat account "gogoboi" is another case in point It is a fashion-debunking official account, and often times, the content creator will also "vomit slot" some celebrities about what they wear at all kinds of occasions such as the movie festival. The number of readers hit $100000+$ most of the times and he has numerous fans in China. Also, he is well acquainted with many celebrities both at home and abroad, so there was no lacking of interviews with them such as Miranda Kerr and Cate Blanchett. Many fans crave for content like that. However, one of the most vital factors for its popularity is not only his own sources, but also the incredible ability to mock others in a very pungent, funny but reasonable way. Another is that the content mostly focuses on the cultivation of fashion sense, in a way that most of the readers can learn and get access to. For example, he often suggests some clothes of unique design, good brand and low price, therefore, it is an eye-catch for most people since being voguish and cool are what most of us would want. Hence, the prosperous future of an Official WeChat Account lies greatly in its closeness with the readers.

These have altogether provided good references for student-run Official WeChat Account in some aspects. Hence, it is recommendable to see things from readers' perspectives, glean as much information about school activities as possible, and employ some hot topics of late so as to hit the pain points and craft great content and layout. Thus, it can be referred that the bad layout design and content straying too far away from college students can explain why academic official accounts usually only attract limited number of readers [7].

\section{SUMMARY}

This article studies the betterment and perfection of student-run Official WeChat Account as a sort of new new media in terms of problems and strategies of fans attraction (WCI), content quality and further improvements in the respect of creativity and ways to strike reader's pain points. These elements may sometimes contradict with each other especially when the administrator pursues one of them solely and neglects the other elements. Therefore, it is significant to strike a balance and reap the most benefits.

For one thing, the essence of Official WeChat Account is to have powerful communication network or WCI given by 
School of Journalism and Communication of Tsinghua University. For another, the mere pursuit of catering to the readers may have negative impact on the content quality as well as the media environment as a whole. We have studied the running of several student-run subscriptions of Anhui University of Technology, which could be used to serve as the case study.

However, the limitation of this essay is that the data and case study are not enough in number and geographic range and there certainly are some other student-run Official WeChat Account in other colleges and universities which may have different running mode than we do due to the size of a city, locations or the orientation of the individual, its department and school. Therefore, a lot of other factors shall also be taken into account so as to effectively and comprehensively ameliorate the media ambience and solve issues induced in the process. This being said, further research can be done with location, subscription type, university orientation and other elements taken into consideration.

\section{ACKNOWLEDGMENT}

This paper has been supported by National Social Science Foundation of China (Project No. 15BYY024), by Excellent
University Youth Talents Supporting Program of Anhui Province, China (Anhui Education Personnel [2014] Reference No.: 181), by Teaching Team Project of AHUT, by John Patrick Tobin, by Huang Yuchen and by Jin Shaokang.

\section{REFERENCES}

[1] P. Levinson, "New New Media," Penguin, 2009.

[2] P. Levinson, "Electronic Text and the Evolution of Media," Journal of Social and Biological Systems, 1990.

[3] Youth League Committee of AHUT, Official WeChat Account: ahuttw, 2016.

[4] X. Liu, "Analysis of Official Wechat Account Content Marketing Strategy," China Academy Journal Electronic Publishing House, vol. 15, pp 213, 2016.

[5] J. Dewey, "The Later Works," 1925-1953. Suthern Illionois Univerisity Press, vol.3, 1984

[6] X. L. Zhang, "Strategies of Cultural Communication in Individual Wechat Subscription "Mimeng"," News Study Guide. China Academic Journal Electronic Publishing House 1994-2017, vol. 19, pp. 304-306, 2016.

[7] W. L. Xie, "Wechat Subscription Service Mode Innovation of Academic Journal in the Era of the Internet," China Technology Journal Studies, vol. 1, pp. 65-72, 2005. 